\title{
Nem só de conceitos vivem as transformações: equívocos em torno da avaliação formativa no ensino/ aprendizagem de línguas
}

Myriam Crestian Chaves da Cunha

Universidade Federal do Pará

Toute théorie livrée à ses pesanteurs tend à s’ aplatir, s’unidimensionnaliser, se réifier, se psittaciser.

Edgar Morin (1990, p. 311)

Este artigo apresenta uma reflexão sobre o modo como, no ensino/ aprendizagem do português língua materna, o conceito de avaliação formativa sofre um esvaziamento ao ser manipulado como senha mágica para a transformação das práticas, sem que as representações às quais se articulam as atividades de ensino/aprendizagem e de avaliação sejam analisadas em seus fundamentos epistemológicos e desdobramentos didáticos. Examinam-se alguns equívocos gerados pela fetichização do conceito, como aqueles perpetrados em torno da pretensa independência das práticas de avaliação do caráter qualitativo dos objetos de avaliação e do caráter contínuo e processual das práticas avaliativas, com o intuito de mostrar a legitimidade de uma avaliação verdadeiramente reguladora no desenvolvimento das competências discursivas.

The purpose of this article is to present how in the learning and teaching of Portuguese as a mother tongue the concept of formative evaluation becomes meaningless when used as a magic wand to transform practices while neglecting the analysis of epistemological foundations and didactic consequences of the corresponding representations. In order to prove the legitimacy of a real regulative evaluation in the development of discursive competences, this article also examines misinterpretations motivated by the fetishizing of the concept such as the presumed interdependency of evaluative practices, the qualitative aspect of evaluative objects and also the continuous and processual aspect of evaluative practices. 


\section{Introdução}

Do mesmo modo que não se pode negar a importância do pão ou de outro alimento material para o sustento da vida humana, seria impossível defender uma transformação das práticas de ensino/ aprendizagem de línguas que não se nutrisse de uma reflexão de ordem metadidática (CUQ, 2003, p. 71). ${ }^{1}$ Entende-se por metadidática uma reflexão visando à objetivação das práticas e à elaboração de um discurso sobre essas práticas, discurso esse "ao mesmo tempo descritivo e especulativo", como o define Cuq (op. cit.), o que envolve necessariamente um trabalho de conceitualização, isto é, de criação de conceitos novos ou de didatização de conceitos pertencentes a outras disciplinas (Cf. GALISSON, 1994).

Porém, se, conforme o preceito bíblico, a satisfação dos anelos humanos fundamentais exige a busca do alimento espiritual que transcenda o pão da cotidiana materialidade, elevar a sofrida realidade dos sistemas educacionais brasileiros a níveis mais dignos, para os sujeitos que neles interagem, demanda muito mais do que a mera convocação de conceitos, por mais substanciais que possam parecer. As práticas precisam ser objetivadas, analisadas e re-elaboradas em novas perspectivas - e os conceitos participam efetivamente desse trabalho de desconstrução/reconstrução - mas aparelho teórico nenhum tem, por si só, o poder de provocar essas mudanças se os conceitos que o sustentam não forem redefinidos e articulados a partir dos contextos concretos nos quais precisam se atualizar.

No âmbito do ensino/aprendizagem de línguas, todavia, age-se com assustadora freqüência como se a solução dos problemas dependesse essencialmente da adequada manipulação verbal dos conceitos autorizados (leia-se dos conceitos mais em voga no momento e que fazem parte do leque de expressões consideradas "didaticamente corretas" na academia). Age-se como se o único fato de despejá-los nos diversos discursos pudesse, como senhas mágicas, fazer as representações

\footnotetext{
${ }^{1}$ Ao lado de muitos outros especialistas, principalmente francófonos, Cuq (2003, p. 71) e Cuq e Gruca (2003, p. 72-73) concebem a Didática das línguas como uma disciplina autônoma, tendo por objeto o ensino/aprendizagem de línguas, e organizada em três níveis operacionais: metadidático, metodológico e técnico.
} 
e a práxis dos sujeitos envolvidos evoluírem, desencadeando assim as almejadas transformações.

A presente reflexão nasceu da observação recorrente desse fenômeno durante a realização de nosso projeto de pesquisa intitulado "A problemática da avaliação no ensino/aprendizagem de línguas", em andamento desde 2003. Tanto no discurso dos professores quanto no de formadores ou responsáveis pedagógicos, em manuais e textos programáticos ou em documentos escolares, alguns conceitos elaborados numa perspectiva mais crítica da avaliação da aprendizagem pareciam assumir um papel primordial, sem que os agentes se apropriassem efetivamente deles na reconstrução de suas práticas.

Nosso propósito aqui não é percorrer atalhos epistemológicos e tentar fazer a gênese dessa atitude, embora, a nosso ver, seja o fruto da tendência fortemente aplicacionista que reina nos estudos atuais do campo do ensino/aprendizagem de línguas no Brasil (ver CUNHA, 2003). Este trabalho limita-se a ilustrar o fenômeno, mostrando, através de seus desdobramentos no campo da avaliação em línguas, mais especificamente por meio do conceito de "avaliação formativa" e de conceitos a ele relacionados, como se manifesta e quanto prejudiciais à efetiva transformação das práticas podem ser os equívocos assim gerados.

\section{A avaliação formativa: um conceito didaticamente correto}

No discurso crítico elaborado, nas últimas décadas, em contraponto às práticas tradicionais de avaliação, ${ }^{2}$ mais especificamente da chamada avaliação da aprendizagem, rejeitou-se a modalidade somativa e o que ela representa em termos de manutenção das desigualdades sociais. Criticou-se a ênfase dada, por meio dessa modalidade, à "função de sanção ou de reconhecimento social do que foi aprendido", que, com "a função de regulação das aprendizagens", são as duas principais funções da avaliação da aprendizagem apontadas por Scallon (1991, p. 10). Segundo refere Afonso (2000, p. 28),

\footnotetext{
${ }^{2}$ Ver, por exemplo, Sant'Anna (1983); Saul (1986); Luckesi (1995).
} 
de acordo com R. Bates (1984), dois propósitos distintivos e por vezes contraditórios podem ser identificados em relação à avaliação escolar: os que se relacionam com interesses e objectivos da administração (managerial evaluation) e os que se relacionam com propósitos e interesses educativos (educational evaluation). O primeiro propósito apóia-se, sobretudo, na avaliação sumativa e normativa ou em testes estandardizados; o segundo propósito apóia-se na avaliação formativa, criterial e diagnóstica [ortografia portuguesa].

De fato, por ela dar absoluta prioridade a funções sócioinstitucionais e estar voltada para a regulação do sistema educacional, a modalidade somativa foi denunciada como um dos principais mecanismos de seleção, de exclusão social, e, por conseguinte, de reprodução dos esquemas de dominação social. Provas, testes e exames, instrumentos privilegiados na lógica classificatória, passaram então a ser considerados como práticas indesejadas.

Opõe-se à concepção acima, que está fortemente ligada à chamada "pedagogia do exame" (Cf. LUCKESI, 1995), uma avaliação formativa, com finalidades pedagógicas, isto é, essencialmente voltada para a regulação da aprendizagem:

Seu objetivo é assegurar uma regulação dos processos de formação, isto é, prover informações detalhadas sobre os processos e/ou os resultados da aprendizagem do aluno a fim de possibilitar uma adaptação das atividades de ensino/de aprendizagem (ALLAL, apud ABRECHT, 1991, p. 25).

Essa modalidade passou geralmente a ser descrita como: contínua (não intervém ao término do processo de ensino/aprendizagem ou de uma de suas etapas, mas integra plenamente esse processo); processual (está mais interessada pelos processos envolvidos na aprendizagem do que pelos resultados obtidos); global (não toma por objeto apenas as capacidades cognitivas do aprendente, mas considera a totalidade de seus comportamentos); qualitativa (não se limita a computar desempenhos observáveis e objetivamente mensuráveis).

Por ter se desenvolvido inicialmente em estreita associação com a pedagogia por objetivos, elaborada com base nos trabalhos de Bloom et al. (1971) e estar ligada a uma concepção behaviorista da aprendizagem, a primeira concepção de avaliação formativa, que se divulgou no mundo educacional a partir dos anos 60, foi rapidamente questionada (ver BONNIOL; VIAL, 1997). A racionalização que se pretendia introduzir 
no projeto educacional foi julgada redutora e os procedimentos pedagógicos nela preconizados foram considerados prejudiciais à formação e à emancipação dos sujeitos da aprendizagem, pois concentravam toda a responsabilidade do processo de regulação (tanto das atividades de ensino quanto da aprendizagem) nas mãos do professor. ${ }^{3}$ Além do mais, na realidade escolar brasileira, com turmas lotadas e professores sobrecarregados pelas más condições de trabalho, a implementação desse tipo de avaliação parecia totalmente impraticável.

As críticas suscitaram numerosas reformulações da proposta formativa, todas elas cunhadas em uma nova denominação: da avaliação formadora (NUNZIATI, 1990) à avaliação participativa (DILIGENTI, 2003), passando pela avaliação emancipatória (SAUL, 1986; BELÉM, 2002), mediadora (HOFFMAN, 1993), qualitativa (DEMO, 1996), dialógica (ROMÃO, 1998), democrática (BATALLOSO, 2003), autêntica (CONDEMARÍN; MEDINA, 2005) e outras propostas de uma avaliação finalmente libertadora, integradora, responsiva, reflexiva, autonomizadora ou reguladora. Praticamente todos os qualificativos focalizando esta ou aquela virtude da nova proposta aparecem na literatura da área.

Diante desse quadro, o conceito de "avaliação formativa" pode ser encarado como uma verdadeira noção, ${ }^{4}$ abrangendo todas essas qualidades esperadas de uma avaliação que participaria plenamente do processo de ensino/aprendizagem, sendo condição sine qua non para a regulação desse processo, para a modificação das relações de poder na sala de aula e para a conseqüente emancipação dos sujeitos neles envolvidos. Não há, hoje, proposta de renovação ou de transformação da realidade educacional que não se refira a essa noção. Quaisquer que

\footnotetext{
${ }^{3}$ Por sinal, esta ainda é a concepção que desponta nos PCN: "A avaliação deve ser compreendida como constitutiva da prática educativa, dado que a análise das informações obtidas ao longo do processo de aprendizagem - o que os alunos sabem e como - possibilita ao professor a organização de sua ação de maneira adequada e com melhor qualidade" (BRASIL, 1998, p. 93) (o grifo é nosso). ${ }^{4}$ A noção pode ser entendida no sentido de "unidade de pensamento constituída por um conjunto de caracteres atribuídos a um objeto ou a uma classe de objetos, que pode ser expressa por um termo ou por um símbolo", segundo o Dictionnaire de linguistique et des sciences du langage (apud CHARDENET, 1997, p. 34) (tradução nossa).
} 
sejam suas manifestações efetivas nos discursos, é hoje incontornável, obrigatória, onipresente. O conceito de avaliação formativa foi alçado, pois, à categoria de conceito didaticamente correto.

No entanto, a análise da realidade revela um angustiante descompasso entre os generosos preceitos veiculados no discurso e as práticas efetivas no cotidiano das aulas de língua (ver CUNHA, 1992; CUNHA, 1998; SOUZA, 2005; BURLAMAQUI, 2005; OLIVEIRA, 2005): embora os termos "corretos" sejam exaustivamente repetidos, as práticas pouco ou nada evoluem. Inútil é dizer quanta frustração é gerada pelo uso inócuo de conceitos que viram chavões pedagógicos, o que fortalece mais ainda a resistência às mudanças. Situações como as que acabamos de apontar repetem-se em sua implacável ineficiência pelo país afora, impulsionadas pela manutenção de alguns equívocos que passaremos a analisar agora.

\section{A independência das práticas avaliativas: uma ilusão tecnicista}

Um dos equívocos perpetrados por uma compreensão superficial da noção que acabamos de apresentar consiste em crer, e principalmente em agir, como se as mudanças na área da avaliação em língua pudessem ocorrer independentemente das concepções existentes a respeito do ensino e da aprendizagem da língua, provocando, por si só, mudanças nesse âmbito também.

Nem a avaliação somativa nem a formativa consistem apenas em um conjunto de procedimentos técnicos e instrumentos que possam simplesmente ser substituídos por outros mais adequados. O modo como se avalia em línguas está em consonância direta com as concepções de ensino, de aprendizagem e de língua predominantes, tanto em nível dos objetivos quanto em nível dos objetos de ensino e de aprendizagem privilegiados (Cf. CUNHA, 1992). Nenhuma crítica consistente das práticas avaliativas no ensino/aprendizagem de língua pode deixar de abranger uma análise dos pressupostos desse ensino/ aprendizagem (o que não é feito pelos estudiosos das ciências da Educação, entre os quais, no entanto, se encontram habitualmente os especialistas em avaliação). No caso do português língua materna, as práticas avaliativas de tipo somativo, que são o alvo principal das críticas, 
estão pautadas numa concepção cumulativa de aprendizagem, numa visão transmissiva de ensino, que assimila os objetos de aprendizagem aos objetos de ensino 5 e faz destes últimos objetos de avaliação. ${ }^{6}$ À medida que se concebe o falar uma língua como o uso correto do código lingüístico e os objetivos de ensino como a manipulação dos metatermos que descrevem o código em questão, os objetos de ensino a serem "retidos" e avaliados consistem essencialmente em um conjunto de conhecimentos declarativos ${ }^{7}$ relativos à terminologia gramatical usual. Como lembra Antunes (2003, p. 87), "o que está em jogo nesse ensino é prioritariamente pretender que o aluno saiba o nome que as coisas da lingua têm" (o grifo é da autora). A crítica à modalidade somativa de avaliação não instaura, por meio de novas técnicas, uma mudança no plano das concepções de ensino, de aprendizagem e de língua.

Com a evolução das concepções a respeito do que seja a língua/ linguagem (de uma visão estritamente sistêmica para uma visão ampliada

\footnotetext{
${ }^{5}$ Entende-se por objetos de aprendizagem, literalmente, aquilo (conhecimentos, habilidades e competências) de que o aprendente deve se apropriar por meio dos atos de ensino. Esses objetos de aprendizagem não se confundem com os objetos de ensino (aquilo sobre o que incide a intervenção didática) que pretendem levar à aprendizagem. Em particular, no caso do ensino de línguas, as competências, complexas por definição, constituem objetos de aprendizagem que não podem ser ensinados diretamente.

${ }^{6}$ Segundo Nunziati (apud BEAUDET; MONNERIE-GOARIN, 1993, p. 59), "os objetos de avaliação são todas as coisas que se quer analisar, medir numa produção" (tradução nossa).

7 Tardif (1992) lembra que "os conhecimentos declarativos correspondem essencialmente a conhecimentos teóricos", isto é, trata-se do "conhecimento de fatos, regras, leis, princípios". Nesse sentido, são conhecimentos "fundamentalmente mais estáticos do que dinâmicos e que, para permitir a ação, devem ser traduzidos em [...] conhecimentos procedimentais ou condicionais" (p. 48). Os conhecimentos procedimentais, também descritos como savoir-faire na literatura pedagógica, "correspondem ao como da ação, às etapas para realizar uma ação, ao procedimento, permitindo a realização de uma ação” (p. 50). Os conhecimentos condicionais, também chamados de estratégicos, "referem-se às condições da ação. Eles concernem ao quando e ao por quê. Em que momento e em que contexto é apropriado usar tal ou tal estratégia, tal ou tal procedimento, iniciar tal ou tal ação? Por que é adequado empregar esta estratégia, este procedimento, realizar esta ação?" (p. 52).
} 
em direção a noções pragmáticas e discursivas de interação), observase atualmente certa modificação nos objetos de ensino. No entanto, a mudança no foco teórico referente à atividade de linguagem (e à aprendizagem da língua materna na escola) não é necessariamente acompanhada por uma mudança na natureza dos objetivos de ensino. Em muitos casos, esses objetivos permanecem limitados à exposição de conhecimentos declarativos, ainda que essas informações não sejam mais relativas apenas ao sistema lingüístico (classes gramaticais ou funções sintáticas) mas também ao texto ou ao discurso (noções sobre tipos de coesão ou definições de gêneros discursivos, por exemplo). Esses conhecimentos, objetos de ensino, que devem ser "aprendidos" - e, portanto, são transformados em objetos de aprendizagem - é que se constituem em objetos de avaliação.

Mudar a metodologia da avaliação (o momento em que se avalia, os instrumentos, os sujeitos da avaliação...) não influi ipso facto na natureza dos objetos avaliados e na função da avaliação praticada. Mudanças nos objetos avaliados são profundamente inter-relacionadas com mudanças nos objetivos de ensino e nos objetos de ensino e de aprendizagem. À medida que os objetivos de aprendizagem em língua materna são expressos, numa perspectiva interacionista (Cf. CUNHA, 2000), em termos de desenvolvimento de competências linguageiras envolvendo saberes e savoir-faire complexos, ${ }^{8}$ é impossível promover uma avaliação formativa que permita uma regulação efetiva da aprendizagem sem que haja uma clarificação da natureza dos objetivos e objetos de ensino a eles relacionados e, conseqüentemente, dos objetos de avaliação. A interdependência entre esses elementos é total.

É profundamente ilusório, portanto, se pensar uma regulação dialógica, mediadora e emancipatória para uma aprendizagem do português na qual "saber português" significa apenas dominar a metalinguagem gramatical, "saber ler" significa apenas decodificar o escrito e "saber escrever" codificar seguindo as normas (orto)gráficas. Não há como se pensar uma regulação dialógica, mediadora e emancipatória em aulas de português que se constroem em torno de

\footnotetext{
${ }^{8}$ Ver a discussão da natureza dessas competências em Hymes (1984), Dolz; Pasquier e Bronckart (1993); Conseil de L'Europe (2000) e Baltar (2004).
} 
objetivos e objetos de ensino totalmente incapazes de conduzir os aprendentes na prática de atividades de linguagem verdadeiramente dialógicas e emancipatórias.

\section{O qualitativo na avaliação: uma noção nebulosa}

A rejeição de práticas avaliativas classificatórias, pautadas na quantificação dos erros dos alunos e na busca de uma suposta objetividade, elevou o adjetivo qualitativo a um lugar de honra na reflexão crítica que se seguiu. Os "conteúdos", objetos de ensino/ aprendizagem/avaliação passíveis de "mensuração", foram designados como vilões do processo e se preconizou sistematicamente a ampliação da avaliação para além dos aspectos cognitivos da aprendizagem: não interessaria mais apenas o aspecto intelectual do processo; por respeito à integralidade da pessoa do aprendente e por entender a sua inserção social, deveriam se incluir os aspectos qualitativos da aprendizagem, abrangendo "a globalidade" ou "o todo do aluno", segundo a hermética expressão consagrada.

A ausência de clareza, anteriormente mencionada, em relação a objetos de aprendizagem significativos levou a uma perigosa indefinição dos objetos de uma avaliação formativa. Passaram a ser incluídos entre os objetos avaliados atitudes e comportamentos, de dentro e de fora da sala de aula, sem que esses tenham sido explicitamente transformados em objetos de aprendizagem. O mesmo problema verificado com o uso abusivo da nota (à guisa de premiação ou castigo para comportamentos individuais ou coletivos dos alunos) pôde então se observar nas práticas em que se buscava agora avaliar essa globalidade. ${ }^{9}$ O perigo não está no fato de se passar a considerar determinadas atitudes como objetos de aprendizagem (e, portanto, de avaliação), e sim de transformá-las em

\footnotetext{
9 Citamos, a título de exemplo, a atitude de um professor que presenciamos numa escola de ensino fundamental em que trabalhamos alguns anos atrás. O referido professor, pensando praticar uma avaliação qualitativa, resolveu atribuir 8,0 como nota final a um aluno que tinha uma média de 10 "nos conteúdos", justificando o fato pelo jeito introvertido da criança que só respondia quando era solicitada a fazê-lo, o que levava o professor a inferir uma falta de interesse da parte da criança.
} 
objetos de avaliação clandestinos, isto é, que não correspondem a objetos de aprendizagem explicitados, em consonância com os objetivos de aprendizagem almejados. Em tais condições, a avaliação, por mais formativa que seja proclamada, passa longe dos anseios democráticos e continua sendo uma arma na mão dos professores.

Em alguns documentos e práticas escolares, a recusa de uma avaliação da aprendizagem limitada à verificação dos conhecimentos (sem a devida análise da natureza desses conhecimentos) levou a uma vertiginosa abertura, na qual tudo e todos eram passíveis de avaliação. Por exemplo, após ter afirmado que "não podemos conceber a avaliação senão como processual, contínua, participativa, diagnóstica e investigativa" (BELÉM, 2002, p. 16), os autores de um manual destinado a apresentar o "Registro síntese", instrumento por excelência da avaliação emancipatória na Escola Cabana, ${ }^{10}$ declaram:

essa abordagem leva-nos a propor que a avaliação não fique centrada no educando e no seu desempenho cognitivo, mas que seja um re-olhar sobre o conjunto da escola, pois as situações de aprendizagem e produção de conhecimento não são responsabilidades de apenas um dos segmentos da comunidade escolar (BELÉM, 2002, p. 17).

Nesse redimensionamento da avaliação para muito além da aprendizagem, acabam se aglutinando a ela objetos de natureza diversa e a avaliação da aprendizagem passa a se confundir com avaliação do ensino, da instituição, das políticas educacionais etc. Avaliam-se desde o envolvimento da família do aluno na escola até o relacionamento do aluno com todos os membros da comunidade escolar ou sua motivação para o estudo. No entanto, como impera, todo soberano, o conceito de uma avaliação formativa necessariamente qualitativa, poucos manifestam sua preocupação com a falta de reflexão em torno dos critérios e dos instrumentos que tal avaliação demandaria (na hipótese de ser possível e desejável um julgamento sobre o "ser" do outro) e com a total subjetividade que a ausência dessa reflexão gerou.

Nessas condições, ocorre um esvaziamento da avaliação da aprendizagem que passa a ser sinônima de redutora, quantitativa e

10 Projeto Político-Pedagógico para a rede municipal de ensino de Belém, implantado na gestão de 1997 a 2004. 
"conteudística", enquanto o global e o qualitativo estão do lado da avaliação progressista. A esse respeito é preciso lembrar a organização em ciclos que, quando implementada com base em uma concepção de avaliação qualitativa, como analisamos acima, acaba eliminando toda e qualquer avaliação da aprendizagem. Isso se dá em detrimento dos próprios aprendentes, iludidos, pela sua constante progressão no sistema escolar, quanto ao estado real de suas competências e que, se não foram "retidos" no ciclo, um dia acabarão marginalizados por não terem desenvolvido as competências necessárias para integrarem-se a programas de formação mais exigentes.

No que tange ao ensino de língua materna, opõe-se uma avaliação dos conhecimentos do aluno sobre as categorias da gramática normativa (em que é fácil quantificar os erros do aluno) a uma avaliação generalizante em que opiniões vagas, expressas em conselhos de classes sobre as supostas competências dos aprendentes nas atividades de linguagem se substituem aos resultados das provas. Em depoimento esclarecedor, uma professora constata:

não conseguíamos sequer explicar algum aspecto da aprendizagem de determinado aluno em língua materna. Podia-se dizer, por exemplo, que $[. .$.$] determinada aluna "deve ficar retida porque não consegue$ interpretar e nem tem o domínio dos conteúdos". Por não termos pensado muito sobre os critérios de avaliação, nem ter definido os objetos de avaliação, não tínhamos muito que dizer (SOUZA, 2005, p. 81).

E conclui:

é espantosa a superficialidade e subjetividade da avaliação que desenvolvemos nessas condições. [...] Isso significa, afinal, que não conseguimos centralizar o Conselho de Ciclo nas questões relativas à aquisição de competências, aos saberes necessários à realização pessoal (Ibid., p. 88).

De fato, não é preciso fugir dos "conteúdos" e perder-se em objetos de avaliação que ultrapassam em muito as preocupações disciplinares. Na realidade, é "conteudística" a exclusiva focalização do ensino de línguas em conhecimentos de natureza declarativa, em saberes conceituais ou factuais (segundo a terminologia usada nos PCN), isto é, em saberes "sobre", cuja "aprendizagem" é claramente insuficiente para permitir a construção das competências complexas envolvidas nas atividades discursivas. Além desse tipo de conhecimentos, tais competências 
abrangem, de fato, savoir-faire e saber-ser múltiplos, ${ }^{11}$ cuja natureza não é exclusivamente cognitiva, uma vez que tais conteúdos se constroem mediante a interação social em atividades linguageiras finalizadas.

O qualitativo está amplamente presente, portanto, nas atividades de linguagem que, em sua multidimensionalidade constitutiva, escapam a qualquer veleidade de descrição puramente objetiva. Nem o saber ler, nem o saber escrever ou falar podem ser caracterizados em termos de certo ou errado. Uma produção escrita, por exemplo, sempre estará sujeita a julgamentos de valor expressos em termos de graus, inscritos numa escala indo do "mais" ao "menos" (ela será mais ou menos adequada do ponto de vista pragmático, semântico, morfossintático ou material ${ }^{12}$ ).

Quando se indaga sobre o sucesso das atividades linguageiras, as únicas respostas possíveis são inevitavelmente interligadas a situações concretas de interação: não há como saber se aquela solicitação foi adequada sem se perguntar com que objetivo comunicacional foi elaborada e a quem se destinava, por exemplo. Nessas condições, refletir, com os aprendentes, sobre as qualidades esperadas em suas produções implica levá-los a depreender e interpretar, no embate com as exigências da interação, o conjunto de critérios que precisam dominar para realizar de forma cada vez mais pertinente as operações necessárias. Apropriarse desses critérios significa construir, na experiência de co-avaliação ou de auto-avaliação, os indicadores ou descritores desses critérios. Para Bonniol (apud BONNIOL; VIAL, 1997, p. 145), aliás, qualitativo e quantitativo não se opõem nesse percurso:

por serem dimensões dos objetivos, os próprios critérios são, em primeiro lugar, qualitativos, abstratos (a coerência de um texto, o rigor de uma análise, o envolvimento de um aluno ou grupo numa tarefa...). Em seguida são traduzidos, convertidos, concretizados por indicadores quantitativos, por categorias de observáveis que poderão ser utilizadas para dar a determinados observáveis o status de indícios.

\footnotetext{
${ }^{11}$ Pode-se também falar em conhecimentos procedimentais e operacionais (na terminologia psicológica - ver nota 6 acima) ou em saberes procedimentais e atitudinais (na dos PCN).

${ }^{12}$ Em referência às categorias usadas na grade de avaliação chamada CLID (Classement des Lieux d'Intervention Didactique) proposta pelo GROUPE EVA (1991).
} 
Embora nem todo indicador seja passível de quantificação, o trabalho de apreensão e apropriação do qualitativo constitui o essencial da construção de competências complexas na aprendizagem da língua. Nessa perspectiva, os critérios ou os indicadores, que são habitualmente categorias de avaliação, transformam-se em categorias de aprendizagem. E o saber avaliar - que implica o domínio dos critérios - passa então a se transformar em objetivo de aprendizagem. Dessa forma, o processo de aprendizagem passa a ser efetivamente regulado. Fica-se, então, muito longe de um "qualitativo" nebuloso, nunca muito bem circunscrito, que não resolve nenhum problema de aprendizagem linguageira e opacifica os objetos de aprendizagem.

\section{A avaliação contínua: um continuísmo mascarado}

Uma das qualidades atribuídas à noção de avaliação formativa é de ser contínua, característica essa que está associada a seu aspecto processual. Tal característica é definida em oposição às práticas somativas tradicionais que ocorrem sistematicamente ao fim de uma "etapa" ou do período de "instrução", limitando-se a verificar o estado dos produtos obtidos, sem possibilidade de retorno: constata-se periodicamente (como dizia jocosamente Luckesi em um vídeo que circulou no Brasil) ${ }^{13}$ que a pneumonia está avançando sem que nenhuma medida terapêutica seja tomada, até se estabelecer o obituário do paciente.

A preocupação com o que ocorre durante o percurso é amplamente justificada no ensino/aprendizagem de línguas em que o desenvolvimento de competências linguageiras múltiplas é um processo demorado, provavelmente nunca acabado. As competências não emergem como mero resultado de uma instrução no âmbito escolar. Para que elas sejam construídas de forma eficiente, é indispensável que o aprendente seja envolvido em interações com finalidade real, e não apenas escolar, nas quais as atividades de linguagem podem adquirir pleno sentido. É óbvio para todos, portanto, que o aprender a produzir e a entender textos orais ou escritos não se concretiza rapidamente, nem de forma homogênea: cada gênero precisa ser apropriado a seu tempo.

${ }^{13}$ Apenas tivemos acesso a uma cópia sem data do referido vídeo, no decorrer dos anos 90 . 
Todavia, a imposição discursiva da noção de avaliação formativa trouxe consigo uma compreensão equivocada do que seja esse "contínuo". Em diversos momentos, professores demonstram entender que, uma vez "livres" da obrigatoriedade das provas com periodicidade fixa, precisam avaliar continuamente: toda produção dos alunos, cada trabalho escrito ou exposição oral passam a ser "avaliados", no sentido de notados. O que se pratica então não é nada menos do que a velha avaliação somativa fragmentada em uma multiplicidade de momentos, uma avaliação somativa constante, mascarada pelo uso do qualitificativo "contínua". Não é determinada uma fase durante a qual a competência visada poderá ser construída, mediante as diversas atividades realizadas na unidade didática em curso, ${ }^{14}$ fase essa em que a verificação não pode ser cristalizada em uma nota ou conceito, e sim só tem razão de ser como diagnóstica e reguladora, isto é, se permitir depreender os problemas a serem superados e apontar caminhos para essa superação.

Essa avaliação contínua está fortemente relacionada ao caráter processual da avaliação formativa, que também suscita confusões quando passa a rejeitar, fora do alcance da atividade avaliativa, os "produtos", como fez com os "conteúdos" aos quais estão sendo assimilados. Nisso ela pretende se voltar exclusivamente para processos, sempre de difícil apreensão em sua natureza amplamente cognitiva. No entanto, valorizar os processos e os procedimentos a eles associados não elimina o interesse pelos produtos nos quais se manifestam. Basta, para isso, não se ter uma representação estática do produto como algo acabado, definitivo, o que seria o mesmo que negar a possibilidade da regulação na aprendizagem. Bonniol (apud BONNIOL; VIAL, 1997, p. 144) sublinha a inter-relação entre processos e produtos:

de fato, é a partir dos resultados parciais (mas um resultado não será sempre parcial?) que os procedimentos utilizados são avaliados, nas relações que determinam com esses resultados: por um lado, os procedimentos utilizados pelo professor em sua gestão pedagógica; por outro, os procedimentos utilizados pelo aluno em seu gerenciamento dos processos de aprendizagem. E é a partir da avaliação desses procedimentos (avaliação do modo como o aluno usa os elementos da situação, os métodos, técnicas, regras, critérios de sucesso, por

\footnotetext{
${ }^{14}$ Ver Dolz; Noverraz; Schneuwly (2005).
} 
exemplo) que o avaliador pode se interrogar a respeito desses objetos virtuais, não diretamente observáveis: os processos [...] que, ao interagir, constituem o Sujeito, o aluno, o grupo de alunos, mas também o professor, a equipe pedagógica, a instituição, os sistemas vivos envolvidos enquanto protagonistas dos processos de mudança.

Em língua, o caráter contínuo da avaliação justifica-se, como vimos, pela lenta construção das competências exercidas em percursos sinuosos. Ao longo do processo de aprendizagem dá-se a construção de uma competência de avaliação necessariamente integrada aos diferentes momentos de produção (facção e refacção do escrito) e de objetivação dessas produções (reflexão de cunho metalingüístico e metalinguageiro ${ }^{15}$ na base das quais se re-escrevem os textos). Tal avaliação não pode deixar de ser também auto-avaliação, não no sentido redutor de uma demagógica "autonotação", e sim de apropriação progressiva de critérios construídos passo a passo mediante atividades metalinguageiras exercidas a partir de atividades linguageiras autênticas. A reflexão sobre as formas que uma produção assume e sobre os recursos lingüísticos mobilizados para que as intenções comunicativas possam se realizar precisa ocorrer em atividades nas quais há, de fato, interlocutores e finalidades reais. Aliás, é somente nessa apropriação que se pode concretizar o caráter dialógico da avaliação formativa, e que se dão aos aprendentes os meios para se tornarem mais autônomos em suas atividades de linguagem, mais independentes na realização de atividades linguageiras eficientes, mais emancipados, enfim.

\section{Considerações finais}

A reflexão aqui apresentada mostra que, por mais bem definido e mais amplamente caracterizado que seja, um conceito, por si só, não possibilita nem uma análise correta dos procedimentos e das escolhas

\footnotetext{
${ }^{15}$ Da mesma forma que lingüistico (ligado à língua, ao sistema lingüístico) opõese a linguageiro (ligado à língua em uso, à dimensão discursiva da linguagem), a atividade metalingüistica refere-se à manipulação de objetos metalingüísticos (terminologia gramatical) e a atividade metalinguageira consiste, segundo a acepção que os psicólogos dão a metalingüístico (Cf. GOMBERT, 1990), na reflexão sobre as atividades de linguagem e no controle (regulação) exercido sobre essas atividades.
} 
que sustentam as práticas tradicionais de ensino/aprendizagem e avaliação em línguas nem, por conseguinte, a renovação dessas práticas. Enquanto se fica em um plano conceitual, sem a devida articulação com o plano didático-metodológico, não há caracterização da avaliação formativa como processual, dialógica, reguladora, etc., que baste para entender em que tipo de atitudes e ações o processual, o dialógico e o regulador, etc., podem se traduzir no cotidiano das aulas de língua materna.

Para ilustrar essa afirmação, podemos pensar o quanto parecem ser evidentes os preceitos educacionais como "seu filho precisa de amor e disciplina”. No entanto, o conselho de um psicólogo dirigido a pais ultrapassados pelo comportamento de seu filho não surtirá efeito algum enquanto pais e filhos tiverem uma representação errônea dos conceitos de amor e disciplina, achando que amar significa não contrariar as vontades de seu filho e disciplinar consiste em extravasar sua irritação na criança, com gritos e tapas. Os conceitos de amor e disciplina precisam ser trabalhados a partir da realidade daqueles sujeitos, para serem percebidos, analisados e investidos em novas atitudes e ações.

No âmbito do ensino de línguas, todavia, muitos estudiosos, em seus gabinetes universitários, comportam-se como conceituados conselheiros que despejam excelentes conceitos nos ouvidos de professores aflitos, sem se preocupar com as representações na base das quais esses conceitos vão ser interpretados. O discurso dominante procede da mesma forma quando manipula a noção de avaliação formativa sem se importar com as representações que essa noção suscita, isto é, quando deixa de trazer à tona e de analisar em seus fundamentos epistemológicos e seus desdobramentos didáticos as concepções nas quais se articulam as atividades de ensino e de avaliação. Essa supervalorização conceitual tem por conseqüência mais imediata o total esvaziamento de uma noção que deveria ter permitido avançar no repensar do ensino/aprendizagem da língua materna e das práticas de avaliação nele efetivadas. O problema, portanto, não se encontra na qualidade ou natureza dos conceitos, e sim na "fetichização" que estes sofrem quando manipulados sem o investimento didático-metodológico correspondente. O problema reside essencialmente em agir como se a sofrida escola brasileira pudesse viver só de conceitos. 


\section{Referências Bibliográficas}

ABRECHT, Roland. L'évaluation formative: une analyse critique. Bruxelles: De Bøeck Université, 1991 (Coll. "Pédagogies en développement").

AFONSO, Almerindo Janela. Avaliação educacional: regulação e emancipação. Para uma sociologia das políticas avaliativas contemporâneas. São Paulo: Cortez, 2000.

BALTAR, Marcos. A validade do conceito de competência discursiva para o ensino de língua materna. Linguagem em (Dis)curso, v. 5, n. 1, jul-dez. 2004. Disponível em: <http://www3.unisul.br/paginas/ensino/ pos/ linguagem/0501/10.htm>. Acesso em: Abr. 2006.

BATALLOSO, Juan Miguel. É possível uma avaliação democrática? Ou sobre a necessidade de avaliar educativamente. In: BALLESTER, Margarita et al. Avaliação como apoio à aprendizagem. Trad. Valério Campos. Porto Alegre: Artmed, 2003. (Col. Inovação pedagógica).

BEAUDET, Suzanne; MONNERIE-GOARIN, Annie. Petit lexique pour mémoire. Le Français dans le Monde. Paris: EDICEF, 1993. p. 57-60.

BELÉM, Secretaria Municipal de Educação. Avaliação emancipatória: registro síntese da práxis educativa. Belém, 2002 (cadernos de educação, v. 5).

BLOOM, B. S.; HASTINGS, J.; MADAUS, G. F. Handbook on formative and sommative evaluation of student learning. New York: Mac Graw Hill, 1971.

BONNIOL, Jean-Jacques; VIAL, Michel. Les modèles de l'évaluation. Textes fondateurs avec commentaires. Bruxelles: De Boeck Université, 1997 (Coll. "Portefeuille/pédagogie").

BRASIL. Ministério da Educação. Secretaria da Educação Fundamental. Parâmetros Curriculares Nacionais: terceiro e quarto ciclo do ensino fundamental: língua portuguesa. Brasília: MEC/SEF, 1998.

BURLAMAQUI, Cristiane Dominiqui Vieira. Uma abordagem interacional e interdisciplinarpara o ensino-aprendizagem do Português no ciclo básico II da escola cabana. 2005. Dissertação (Mestrado) - UFPA, Belém.

CHARDENET, Patrick. L'évaluation: parcours notionnel et faits discursifs. Etude d'une notion à travers les discours circulant dans l'enseignement des langues et du français langue étrangère. 1997. Thèse (Doctorat) - Université de la Sorbonne Nouvelle-Paris III, Paris. 
CONDEMARÍN, Mabel; MEDINA, Alejandra. Avaliação autêntica: um meio para melhorara as competências em linguagem e comunicação. Trad. Fátima Murad. Porto Alegre: Artmed, 2005.

CONSEIL DE L'EUROPE. Division des langues. Cadre européen commun de référence pour les langues: apprendre, enseigner, évaluer. Paris: Didier, 2000.

CUNHA, Myriam Crestian Chaves da. A problemática da avaliação no ensino/ aprendizagem do Português. 1992. Dissertação (Mestrado) - Universidade Federal do Pará, Belém.

Une approche interactionnelle pourl'enseignement/apprentissage du portugais langue maternelle: intégration de l'évaluation formative à la démarche didactique. 1998. Thèse (Doctorat) - Université de Toulouse IILe Mirail, Toulouse.

. Uma abordagem interacional para o ensino-aprendizagem do português: condições e características. In: CUNHA, J. C.; CUNHA, M. (Org.). Pragmática lingüistica e ensino-aprendizagem do português: reflexão e ação. Belém: UFPA, 2000. p.23-54.

. O ensino-aprendizagem de línguas: um campo à procura de uma disciplina. Moara, Revista dos cursos de pós-graduação em Letras, Belém, n. 19, p. 9-37, 2003.

CUQ, Jean-Pierre (Coord.). Dictionnaire de didactique du français langue étrangère et seconde. Paris: Clé International, 2003.

CUQ, Jean-Pierre; GRUCA, Isabelle. Cours de didactique du français langue étrangère et seconde. Saint-Martin-d'Hères (Isère): Presses Universitaires de Grenoble, 2003.

DEMO, Pedro. Avaliação sob um olharpropedêutico. Campinas: Papirus, 1996.

DILIGENTI, Marcos Pereira. Avaliação participativa no ensino superior e profissionalizante. Porto Alegre: Mediação, 2003.

DOLZ, Joaquim; PASQUIER, Auguste; BRONCKART, Jean-Paul. L'acquisition des discours: émergence d'une compétence ou apprentissage des capacités langagières diverses? Etudes de Linguistique Appliquée, Paris, n. 92, p. 23-37, oct-déc. 1993.

DOLZ, Joaquim; NOVERRAZ, Michèle; SCHNEUWLY, Bernard. Seqüências didáticas para o oral e a escrita: apresentação de um procedimento. In: SCHNEUWLY, Bernard; DOLZ, Joaquim. Gêneros orais e escritos na escola. Trad. Roxane Rojo. Campinas: Mercado Livre, 2005. p. 95-128. 
GALISSON, Robert. Formation à la recherche en didactologie des languescultures. Etudes de Linguistique Appliquée, Paris, n. 95, p. 119-159, juillet.septembre 1994.

GROUPE EVA. Evaluer les écrits à l'école primaire. Paris: Hachette, 1991.

HOFFMAN, Jussara. Avaliação mediadora: uma prática em construção da pré-escola à universidade. Porto Alegre: Mediação, 1993.

HYMES, Dell H. Vers la compétence de communication. Trad. F. Mugler. Paris: Hatier/CREDIF, 1984.

LUCKESI, Cipriano Carlos. Avaliação da aprendizagem escolar. São Paulo: Cortez, 1995.

MORIN, Edgard. Science avec conscience. Nouvelle édition. Paris: Seuil, 1990. (Coll. "Points").

NUNZIATI, Georgette. Pour construire un dispositif d'évaluation formatrice. Cahiers Pédagogiques, Paris, n. 280, p. 47-64, 1990.

OLIVEIRA, Andréia dos Santos. Para uma avaliação formativa da produção oral em turmas de Francês Lingua Estrangeira. 2005. Dissertação (Mestrado) - Universidade Federal do Pará, Belém.

ROMÃO, José Eustáquio. Avaliação dialógica: desafios e perspectivas. São Paulo: Cortez, 1998. (Guia da Escola Cidadã, v. 2).

SANT'ANNA, Flávia M. Uma análise crítica da avaliação educacional. In: PADES; UFRGS; PROGRAD. Avaliação da aprendizagem: enfoques teóricos. Porto Alegre: UFRGS, 1983.

SAUL, Ana Maria. Avaliação emancipatória: proposta democrática no contexto de avaliação educacional. In: CAPELLETI, I. F.; MANSETTO, M. T. (Org.). Ensino superior: reflexões e experiências. São Paulo: EDUC, 1986.

SCALLON, Gérard. L'évaluation formative des apprentissages: la réflexion. Tome 1. Québec: Presses de l'Université Laval, 1991.

SOUZA, Cláudia Nazaré Gonçalves de. O ensino/aprendizagem do português e a avaliação emancipatória: repensando a experiência da Escola Cabana. 2005. Dissertação (Mestrado) - Universidade Federal do Pará, Belém.

TARDIF, Jacques. Pour un enseignement stratégique: l'apport de la psychologie cognitive. Montréal: Logiques, 1992. 
$+1$ 